\title{
Empirical Evaluation of Art and Design Students' Online Assessments: A Case of Construct Validity Analysis at STEP
}

* Gouhar Pirzada, MPhil Scholar (Corresponding Author)

** Dr. Fariha Gul, Assistant Professor

*** Saima Yaqub, Lecturer

\begin{abstract}
Educational institutions are bound to take online assessments due to pandemics, which drives the need to identify the perceived satisfaction of both teachers and students about the effectiveness of this process. The current study aims to explore perceptions of Art \& Design students and teachers since the issue becomes even more complex due to the practical nature of these subjects and assessments. A total of 157 students participated in this research study, whereas the data is collected through convenient sampling. The data from teachers was collected through a focus group discussion. The purposive sampling process was used for this purpose. A self-developed survey instrument was used to collect data with an alpha value of .73. The results of the survey indicate the satisfaction of students with the process and effectiveness of online assessment. Demographic analysis includes current qualifications (mean=2.69), previous qualifications (mean=.41), current working status of students (mean=.96), and students enjoying any scholarships (mean=.39) etc. The data collected through focus group discussion was studied through thematic analysis techniques. The results of the study promised to help in designing and implementing strategies when conducting online assessments particularly for Art \& Design qualifications.
\end{abstract}

Keywords: Online Assessments, Construct Validity, Art \& Design, Empirical Evaluation, Learning Outcomes

\section{Introduction}

The past couple of decades has proven to be times of emerging developments and drastic changes in the field of information, communication, and technology. Most vital changes that are possibly more vibrantly observed are the ones where these developments directly create an impact on society; the origin of the internet. The rapid inclusion of the internet has become a pervasive part of everyday life. This has changed the working practices of many professions: among them, those engaged with the field of education also changed. These include the integration of information from online classes and then evaluation of students through online assessments (Allen \& Seaman, 2014). Subsequently, online learning technologies are being widely adopted across the globe in different educational institutes but what is more significantly interesting is the critical issue of evaluating it and how these technologies help enhance students' learning outcomes and their assessments.

With the global epidemic of Covid-19, it has become necessarily important and inevitable in certain cases, to utilize these online learning technologies in the field of education to enable the support of educational mechanisms that have been designed to achieve high-level outcomes (McCall, 2010). There are a variety of renowned techniques that designers can see while evaluating students from an online assessment (Adelstein \& Barbour, 2016). Institute of Art, Design \& Management at STEP, for instance, introduced the concept of blended learning to reinforce delivery and assessment of course designs for their graduate-level Art \& Design qualifications. Educational institutes use a blend of learning strategies in their approaches to delivering the right content in the right design to the right audience at the right time. Blended learning is a program that includes different forms of learning tools that may include, real-time virtual software, web-based courses, and electronicperformance-based system associated with job environment and management systems (Poon, 2013).

\footnotetext{
* University of Management \& Technology (UMT), Lahore

** University of Management \& Technology (UMT), Lahore

*** Onaizah Colleges, Saudi Arabia
} 
In the past decade, there has been a rapid increase in empirical research usage in the education sector to evaluate students' learning through online courses and assessments. However, the existing research somehow lacks the strong theoretical and methodological based issues, specifically in the Art \& Design suite of qualifications. In general, the methodological problem of construct validity is particularly ignored or has been of lesser focus. The current study aims to identify the perceptions and practices of students enrolled in Art \& Design qualifications to fill the gap of empirical evidence in the aforementioned areas by using the unique features of construct validity.

This research evaluates effective outcomes by comparing the results of online assessments with regular assessments that were conducted previously. It attempts to focus on the evaluation of Art \& Design students' online assessments as perceived by students, which were conducted for the first time in the institute. The processes behind the development of different evaluation standards serve as the basis of this research. However, to gain a greater impact on the field, it centrally focuses to analyse the case from construct validity standards. Finally, suggestions are provided for improving future processes and prospective assessment related areas.

\section{Conceptual Framework}

Below is the conceived conceptual framework being followed for this research study, which signifies that construct validity of Art \& Design online assessments could lead to achieving students' learning outcomes. Although, the process is inevitably impacted by appropriate planning and implementation strategies. Theoretically, the framework strongly advocates the notion of attaining set learning outcomes, which are objectively defined and stated against each unit (course) in the vocational outcome-based education. It is important to note the all three learning domains, 'knowledge, skills and attitudes', are emphasized while drafting the unit outcomes by an international awarding body, i.e. Pearson, UK. This becomes a key challenge for assessors to ensure construct validity of Art \& Design online assessments is applied in its full spirit. This paper is an effort to reveal issues and areas that are covered under planning and implementation assessment strategies, to sustain the whole process. The study aims to analyze the planning and implementation of assessment strategies through the lenses of both qualitative and quantitative research methods. The following figure explains the conceptual framework of the study;

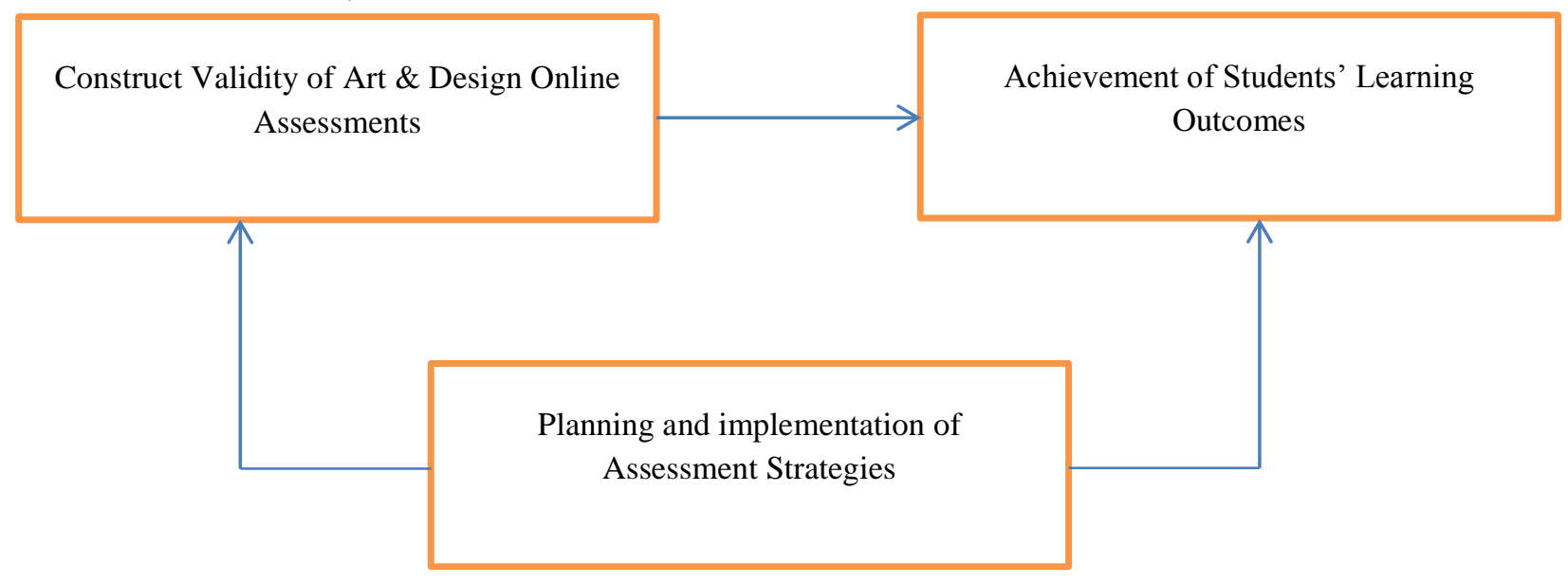

\section{Literature Review}

Fig. 1 Conceptual framework of the study

One central concern about online assessment techniques is whether desired learning outcomes in online mode are achieved in a similar way as students involved in regular paper-based assessments. While including information technology in evaluating students' learning outcomes, there involves multiple levels and types of risks. A major risk among these is the issue if assessments are as valid as the traditional face to face / on-site assessments. Online assessments, also known as, digital assessment, electronic assessment, or computer-aided assessment, usually make it difficult for designing evaluation techniques. A related and equally important question and the central focus of the present research remains whether the online assessments are as valid as traditional offline assessment methods. Additionally, the students' previous qualification related to technology also helps in accessing their empirical evaluation related to current online assessments. This pre-existing competency and familiarity help them to adopt the new technological system faster than those 
students who were not having any IT background (Dumford, 2018). Therefore, demographic analysis of students is equally significant to be understood while examining the best practices required to adopt in the current pandemic of Covid-19. Furthermore, the validity of the online assessment techniques is also questionable if the factors of desired students' learning outcomes do not relate to their performance in the online test designs.

Validity is defined as a degree through which a concept or measurement is well-founded and correctly measured according to the real world (Carmines \& Zeller, 1979). The central aim of this research is concerned with the validity of data obtained regarding online assessments. The present study is a research-based on the first-time online assessments conducted at STEP Institute of Art, Design \& Management. The present research is unique as it includes students from various specialized areas of Art \& Design undergraduate qualifications and evaluation of the results from online assessments would highlight some main concerns. Specialized areas represented by participating students include Fashion Design, Textile Design, Interior Architecture Design, and Graphic Media design. Standard terms of 'online' and 'computer-based' assessments within the literature are used for a comprehensive understanding. Additionally, analysis of students' performance on basis of their existing financial backgrounds also provides useful insights for empirical evaluation regarding online assessments. This aspect includes issues; if they are availing any scholarships! (Arias, 2018). Similarly, students' prior knowledge of the Art \& Design subject is also important to examine as this might also help them to adopt best practices during online assessments. Eventually, unreliable information related to technologies is certainly a prominent threat to the validity of computer-based assessments.

Validity is further analyzed through the methods of constructs and content validity to accomplish this research. Construct validity determines how much a certain concept is related to other similar measures to determine that a test measures what it claims to measure (Carmines \& Zeller, 1979). From the past decade, there has been an increase in the field of online-based assessment methods but a large portion of this research is lacking a resilient conceptual subject. Mostly, the methodological issue of construct validity is usually ignored. It is one critically important aspect to check the adequacy of measures in the process of construct validation. However, strong, repeatedly tested, and strong systems have now been shown that offer reliable methods for implementing online assessments, which were previously thought as less reliable or credible. Content validity is also considered important to undergo this research, implied by including the content of the measures according to the specific requirements. Content validity is defined as the extent to which the defined concept includes all related facets of the particular concept. Content validity measures at the preliminary stage of scale explanations by creating a set of units and succeeding evaluations by experts (Netemeyer, Bearden, \& Sharma, 2003).

\section{Statement of the Problem}

This research study on empirical evaluation of art \& design students' online assessments in the pandemic of Covid-19 promises to address and contribute towards effective application and implementation of online assessments. Firstly, it will help to understand the importance of perceived students' satisfaction concerning online assessments in Art \& Design studies. Secondly, it is important to understand the demographics variables in developing students' perceptions towards online assessments. Lastly, this study promises to help examine and understand teachers' perceptions while conducting online assessments.

\section{Objectives of the Study}

On basis of the central aims of this research, the following three research objectives were designed for this study;

1. To explore the perceived satisfaction of students concerning online assessment in Art \& Design undergraduate qualifications.

2. To identify the role of demographic variables in developing perceptions towards online assessments.

3. To explore perceptions of teachers about the effectiveness of online assessments in Art \& Design qualifications.

\section{Research Questions of the Study}

On basis of the aforementioned objectives, the following research questions were devised; 
1. What is the level of perceived satisfaction among students concerning online assessments in Art \& Design qualifications?

2. Do demographic variables (including gender, previous education, or subject knowledge) influence the perceptions of students regarding online assessments?

3. What is the perceptions of teachers about the effectiveness of online assessments?

\section{Methodology}

\section{Research Design}

The survey research design was used to obtain the objectives of this study. Participating students were enrolled with STEP Institute of Art, Design and Management, which is a private sector institute located in Lahore and offering international vocational Art \& Design qualifications since 2003. Formal permission of Institute authorities was taken before commencing research. Data collected from the students was then validated through a focus group discussion among teachers who were teaching to those students and were part of the online assessments. The mixed-method approach helped to validate the responses other than providing a clearer picture of the process of online assessment of Art \& Design qualifications.

\section{Population and Sample}

The targeted population of the study includes students enrolled in the STEP Institute of Art, Design, and Management. 157 students out of a total of 360 students who have enrolled in various Art \& Design specialized undergraduate qualifications, participated in the research. The faculty of the Art \& Design and Students Services department greatly assisted in smooth facilitation and data collection activities engaging the students. The sample was extracted through convenient sampling. The instrument was developed using google forms and an email was sent to all students of the school. Students who responded were considered part of the study, thus making a total of 157 students $(\mathrm{F}=97$; $M=60)$ to be part of the sample of the current study. Data was collected from all stages $\left(1^{\text {st }}\right.$ year, $2^{\text {nd }}$ year, $3^{\text {rd }}$ year, and $4^{\text {th }}$ years) of undergraduate programs with specialization in Fashion Design, Textile Design, Interior Architecture Design, and Graphic Media design.

The second part of the study was carried out by taking data from teachers and assessment administrative staff about the effectiveness of online assessment in Art \& Design. Currently, 37 fulltime teachers are part of the Art \& Design faculty at the institute, out of which, 12 faculty members consented to voluntarily participate in the focus group discussion. The faculty head and Human Resource department helped in scheduling the focus group session with teachers. A prior consent was taken from the organization and participants for conducting and recording the online discussion, so that data can be transcribed later.

\section{Instrument of the Study}

Two instruments were used to collect data from the respondents, as two different strata (teachers, and students) participated in the study.

a. A survey instrument to examine the perceived effectiveness of online assessment.

b. A focus group manual for discussion with teachers on the perceived effectiveness of online assessment.

A brief description of each instrument is given below;

a. The first instrument was adapted from the student perceptions of the e-assessment questionnaire by John Dermo (2008), University of Bradford. Items were not fully adopted as they were presented in the questionnaire but some of these were enhanced to an extent, based on lesser development in technology and lesser technology-orientation of the country of research. The instrument was mainly composed of six factors including Validity (5 items), Reliability (5 items), Security (5 items), Affective factors (5 items), Pedagogy (5 items), Practicality (5 items), and Content validity (4 items).

\section{Pilot testing of the Instrument}

The instrument was pilot tested before administering on the sample for research. The following table presents the reliability statistics in form of the Cronbach's Alpha values of each variable.

Table 1. Reliability of the survey instrument

\begin{tabular}{ccc}
\hline Factors & Cronbach's Alpha & N of Items \\
\hline Affective Factors (AF) & 0.96 & 5 \\
Validity (VAL) & .421 & 5 \\
Practicality (PRAC) & .348 & 5
\end{tabular}




$\begin{array}{ccc}\text { Reliability (REL) } & .377 & 5 \\ \text { Security (SEC) } & .491 & 5 \\ \text { Pedagogy (PED) } & .365 & 5 \\ \text { Content Validity (CV) } & .703 & 4 \\ \text { Total } & .738 & 30\end{array}$

b. The second instrument used for this research was the focus group protocol, which was based on factors relevant to the effectiveness of online assessment for undergraduate qualifications. Informed consent was collected from all participants for the recording of online focus group meetings. The statements of the protocol included factors that would help to analyze participants' perceptions in terms of students' capabilities, course coverage, assessment security and accessibility, practical and theoretical knowledge, students' scores, and their personal experiences of online assessments. Responses from teachers were later compared

\section{Data Analysis} and contrasted with the responses of similar questions when asked from students.

As mentioned above, the data was collected in two modes; one from students through surveys and the second from teachers through focus group discussion. Results are discussed below according to the mode of data collection, concerning the objectives of the study. The spread of sample and percentage of demographic variables is given below;

Table 2. Spread of sample and percentage of demographic variables

\begin{tabular}{ll}
\hline Variables & Percentage (\%) \\
\hline Gender: & 37.6 \\
Male & 62.4 \\
Female & \\
Current Education: & 40.1 \\
Fashion Design & 26.1 \\
Textile Design & 12.7 \\
Interior \& Architecture Design & 21.0 \\
Graphic Media Design & \\
Current Year of Study: & 17.8 \\
Year 1 of Undergraduate degree & 25.5 \\
Year 2 of Undergraduate degree & 26.1 \\
Year 3 of Undergraduate degree & 30.6 \\
Year 4 of Undergraduate degree & \\
Previous Qualification: & 77.7 \\
Intermediate/FA & 9.6 \\
A-Level/GCE & 6.4 \\
UK National Diploma/Vocational A-Level & 6.4 \\
Other & \\
Previously studied Art \& Design related subject: & 33.8 \\
Yes & 66.2 \\
No & \\
Previously studied IT Subject: & 28.0 \\
Yes & 72.0 \\
No & \\
Currently Working: & 19.0 \\
Yes & 81.0 \\
No & \\
Availing any Scholarship: & 60.5 \\
Yes & 39.5 \\
No &
\end{tabular}

Table 2. presents frequencies of demographic variables. The 157 respondents are dominated by females (62.4 percent) than males (37.6 percent), and a higher number of students are currently enrolled in the Fashion design qualification (40.1 percent) comparing to the other three programs of studies, which are offered at STEP and which are part of this research study. While maximum students in the data set represent the last year of their undergraduate program, i.e. 30.6 percent. Moreover, a higher number of students contains an intermediate/FA degree ( 77.7 percent) as their previous qualification. While responding to the question about any Art \& Design related course studied as a subject in their previous studies, a higher number of students reveal they have not studied 
it as part of their previous qualification (66.2 percent). However, a higher number of students have studied IT courses as a subject of their previous qualification (72 percent). Additionally, when asked about their work status, a higher number of students do not work currently (81 percent). Lastly, a higher number of students from the selected cohorts are studying in the institute on a scholarship $(60.5$ percent) based on their previous academic performance or financial needs.

\section{Objective 1. Perceived satisfaction of students concerning online assessment:}

As part of measuring the online assessments at STEP, a survey was carried out for students, faculty, and assessors' perceptions. The quantitative method approach is applied in investigating the objective and subjective matter of the phenomenon. The instrument of quantitative analysis is created, keeping in mind the elements or factors related to online assessment techniques. The survey questionnaire looked for 6 main dimensions based on the literature of online assessments that include affective factors, validity, practicality, reliability, security, and pedagogy. The targeted population includes participants that are currently engaged with the process of online assessments and also previously with regular assessments of similar courses. The survey was conducted based on convenient sampling from students, faculty members, and assessors of STEP who are engaged within the online assessment processes. The instrument measures all constructs with the results of means and standard deviation that are presented in the table below.

Table 3: Level of perceived satisfaction of students concerning online assessment

\begin{tabular}{ccc}
\hline Factors & Mean & Standard Deviation \\
\hline Affective Factors (AF) & 3.3731 & .52158 \\
Validity (VAL) & 3.1871 & .60116 \\
Practicality (PRAC) & 3.3419 & .53693 \\
Reliability (REL) & 3.2013 & .58121 \\
Security (SEC) & 3.1167 & .62793 \\
Pedagogy (PED) & 3.0713 & .54866 \\
Content Validity (CV) & 2.9885 & .80063 \\
Total & 22.2799 & 4.2181 \\
\hline
\end{tabular}

Objectives 2. Influence of demographic factors on Students' perceptions about online assessment:

The second objective of the study was to identify the role of demographic factors in developing positive perceptions about online assessment. One sample t-test was applied to check for differences in mean among the demographic variables. The one-sample t-test identifies if the value being tested for the sample is true or false. For this test, the demographic variables were tested for the assumption that the mean of the selected group is significantly different from zero. The tests for all variables are significant, that is, their significance value is less than the alpha value of .05 , therefore, the assumption that these variables have a sample mean of zero is rejected; all variables have means which are different than zero.

Table 4. Mean difference based on demographic factors on perceptions of students about online assessment

\begin{tabular}{|c|c|c|c|c|c|}
\hline Variables & & df & Mean & t-value & Sig. \\
\hline Gender & $\begin{array}{l}\text { Male } \\
\text { Female }\end{array}$ & 156 & .62 & 16.097 & .000 \\
\hline $\begin{array}{l}\text { Previous degree in } \\
\text { Art \& Design }\end{array}$ & $\begin{array}{l}\text { Yes } \\
\text { No }\end{array}$ & 156 & .66 & 17.496 & .000 \\
\hline $\begin{array}{l}\text { Previous knowledge } \\
\text { of IT }\end{array}$ & $\begin{array}{l}\text { Yes } \\
\text { No }\end{array}$ & 156 & .72 & 20.016 & .000 \\
\hline Status of studentship & $\begin{array}{l}\text { Full-time } \\
\text { student } \\
\text { Part-time } \\
\text { student }\end{array}$ & 156 & .96 & 20.527 & .000 \\
\hline Financial support & $\begin{array}{l}\text { Self-paying } \\
\text { Scholarship }\end{array}$ & 156 & .39 & 10.090 & .000 \\
\hline
\end{tabular}

$\mathrm{N}=157$

There was a significant mean difference based on gender. Therefore, both have different responses to the research questions (Mean=.62). Similarly, a significant difference $(p=.000 ; t=17.49)$ was found based on a previous degree in art and design with a mean value of .66. The students with 
previous knowledge of computer as part of their previous study programs (mean=.72) also seems satisfied with online assessment with $(\mathrm{p}=.000 ; \mathrm{t}=20.1)$. The status of studentship and financial support also has a positive influence in differentiating the perceptions of students about online assessment with t-values 20.25( $\mathrm{p}=.000)$ and $10.09(\mathrm{p}=.000)$ respectively.

Objective 3. Perceptions of teachers about the effectiveness of online assessment in Art \& Design subjects:

The third objective of the study was to validate the opinion of teachers about the perspective of students on the effectiveness of online assessment in Art \& Design qualifications. For this purpose, an online focus group discussion was carried out. In total 12 participants voluntarily participated in the online discussion to bring together and discuss the challenges associated with the process of online assessments, as part of the qualitative method. The group included teachers, program coordinators, and assessment administrative staff, engaged with the process of online assessments. Focus group is a well-known technique in qualitative research that helps in easy and quick measuring respondents' reactions to a research phenomenon. This method allows the researcher to gather rich data with reduced expense and less time. The collective conversation among related stakeholders in a focus group help to compare and contrast the result derived from current online assessments with previous regular assessments. Qualitative techniques help to gain a deeper understanding of the concept under research and this sort of analysis is always opened for interpretations. The flexible nature of focus group methodology makes it attractive as the researcher has a great deal of margin in gathering respondents' different viewpoints and therefore, the discussion reflects the researcher's concerns.

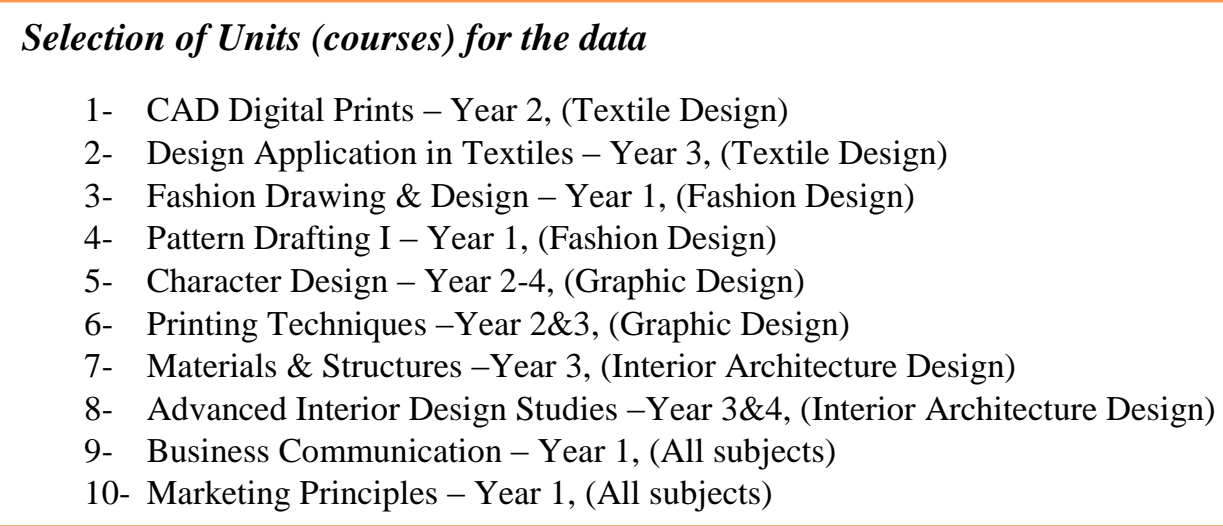

The above table suggests the ten units (courses) selected from the four specialized areas of Art \& Design at the undergraduate level. Selection of courses is carefully made, following the multiple skills being taught at various levels and years of their studies including the design skills, conceptual skills, digital skills, and management skills. Attempt of including assessors with multiple specialized areas have been made while selecting the courses.

Applying the Conceptual framework through the quantitative lens:

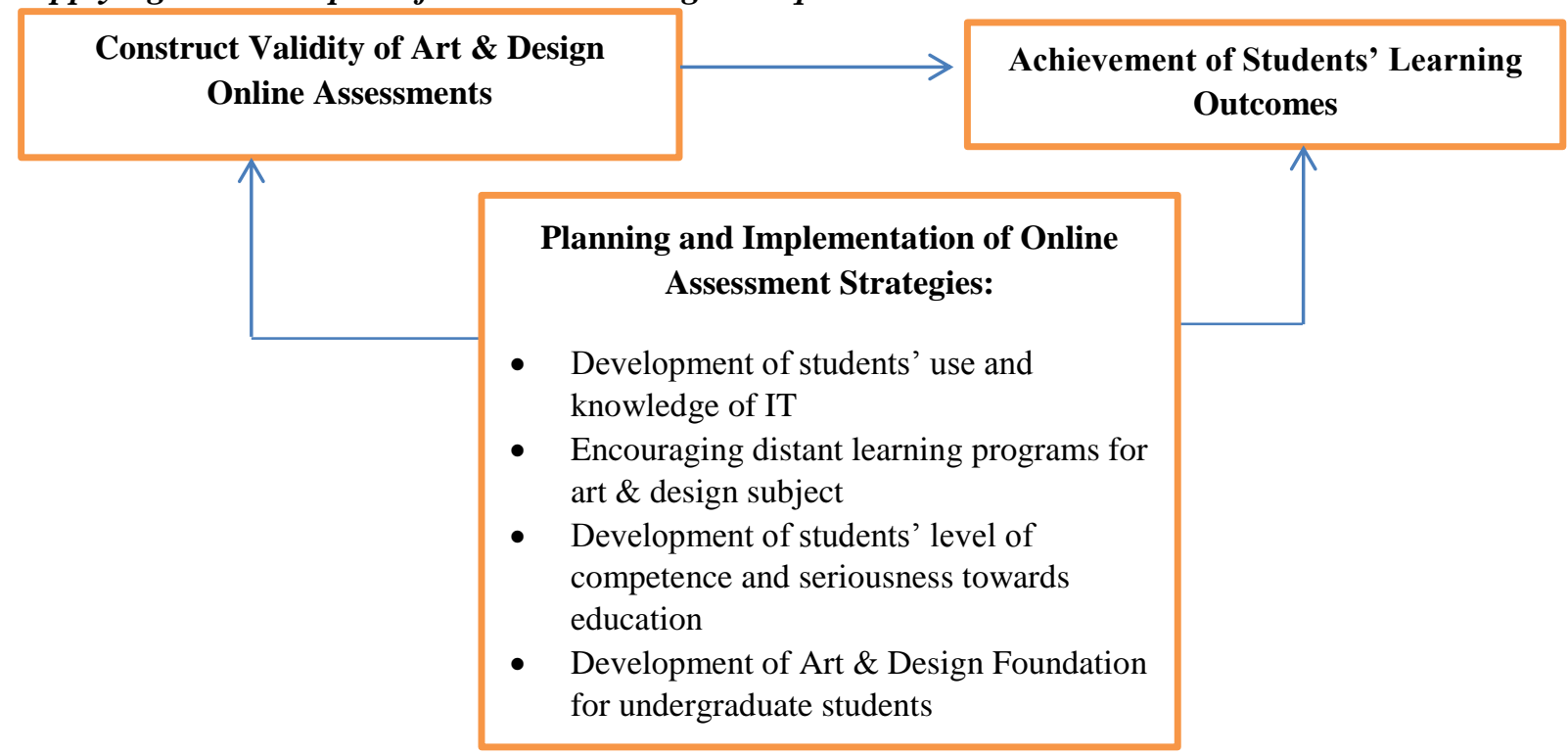


The analysis from the focus group resulted in six major themes that can be analyzed through the graph and each one of these is discussed below.

\section{Major Thematic areas:}

\section{Students' capabilities}

Assessments are always mean to measure the student's capabilities. Therefore, online assessments must evaluate the students' capabilities. Most participants in the focus group responded that they achieved all the learning outcomes from online assessments.

\section{Students' scores}

The evaluation of students' scores is also an important theme that emerged from the data of the focus group. On average, students' scores do not show any unusual pattern as per most of the participants. The high scorers continue to lead and the average performers sustain their grades in both types of assessments. Scores for each unit differ according to the desired outcomes that are meant to be achieved from each unit, followed in light of the international awarding bodies.

\section{Accuracy of online assessments}

While discussing the accuracy of online assessments, most respondents consider online assessments to be more accurate than paper-based assessments. They found online assessments more correct and precise for their perspective units rather than previously conducted paper-based assessments of the same units.

\section{Security and Accessibility of online assessments}

In the context of security and accessibility of online assessments, most respondents realize that the content is, both secured and accessible for students during assessments. Although, it mainly depends on the nature of each unit and the learning outcomes, which are desired to be achieved from the respective units.

\section{Content analysis}

Concerns on coverage of maximum content in online assessments are dominantly felt by the majority of participants. The need of covering further content in assessments is even more relatable to Art \& Design qualifications. Most of the respondents accept that there remains important and technical content being missed in the current online assessments, which need to be achieved and assessed by students, specifically for units with technical learning outcomes. However, participants also expect significant improvement in future online assessments, in terms of their format, methodologies, and exam patterns. The recent online assessment, being the first-timer has provided adequate learning and experiences of identifying the weaker areas, and this promises to open new opportunities for effectively assessing online in the future.

\section{Knowledge practices}

While discussing the practical and theoretical knowledge from online assessments, most respondents show concerns about the assessment of skills-oriented areas and outcomes for related technical and digital subjects. The discussion highlights the further need to achieve the desired knowledge outcomes from the students. This promises to be an improved aspect for future online assessments for these units.

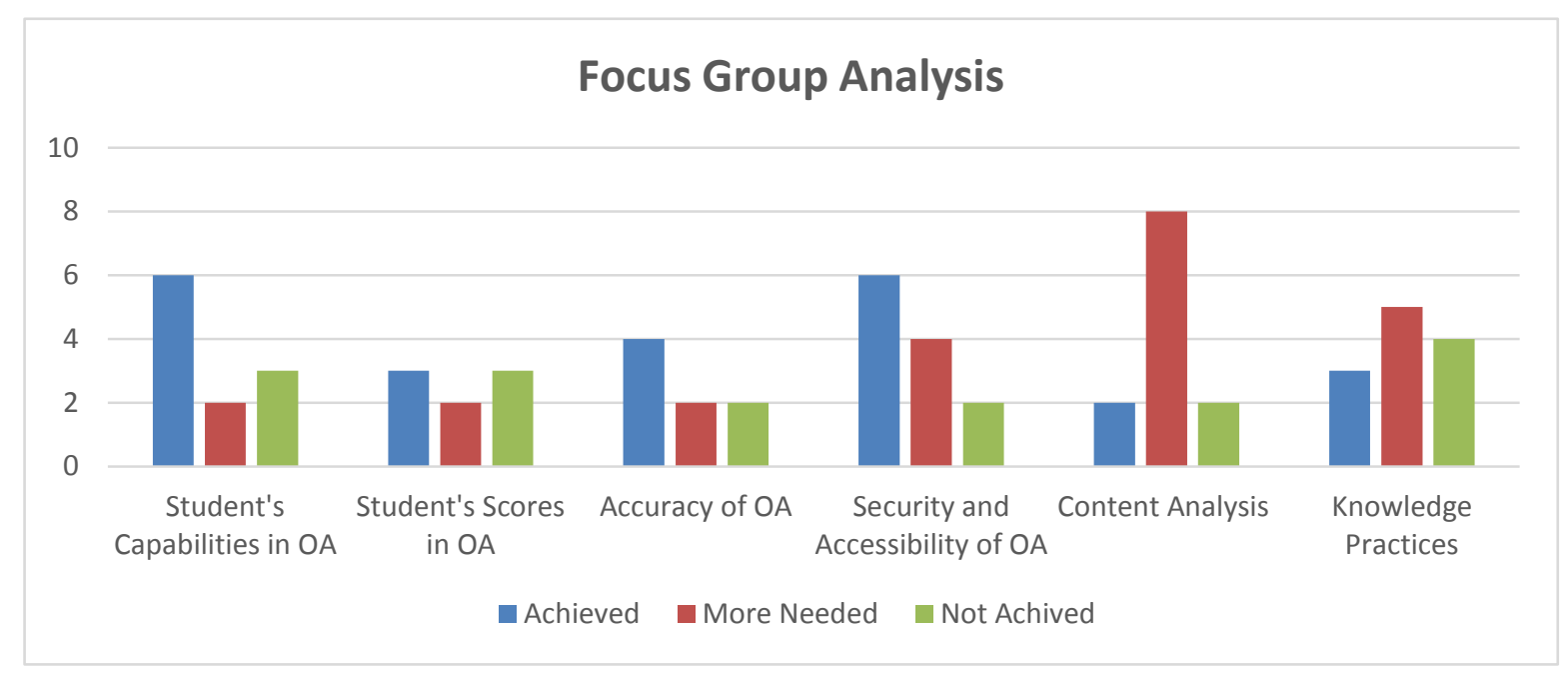




\section{Conceptual framework through the qualitative lens:}

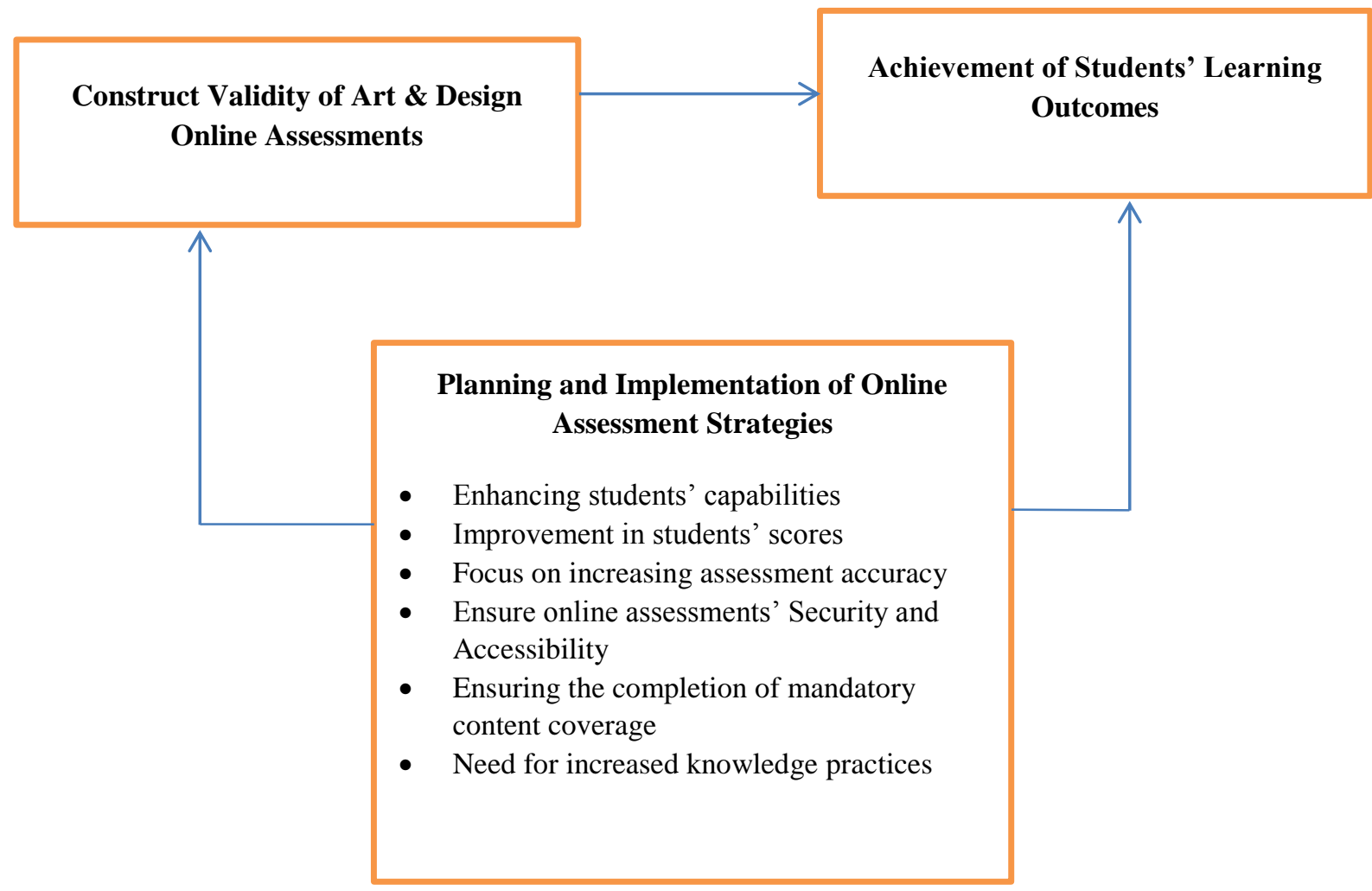

Findings from the qualitative research method leads further in suggesting elements that could concrete the planning and implementation strategies for online Art \& Design qualification. The six thematic areas could serve as the basis of the foundation for these strategies.

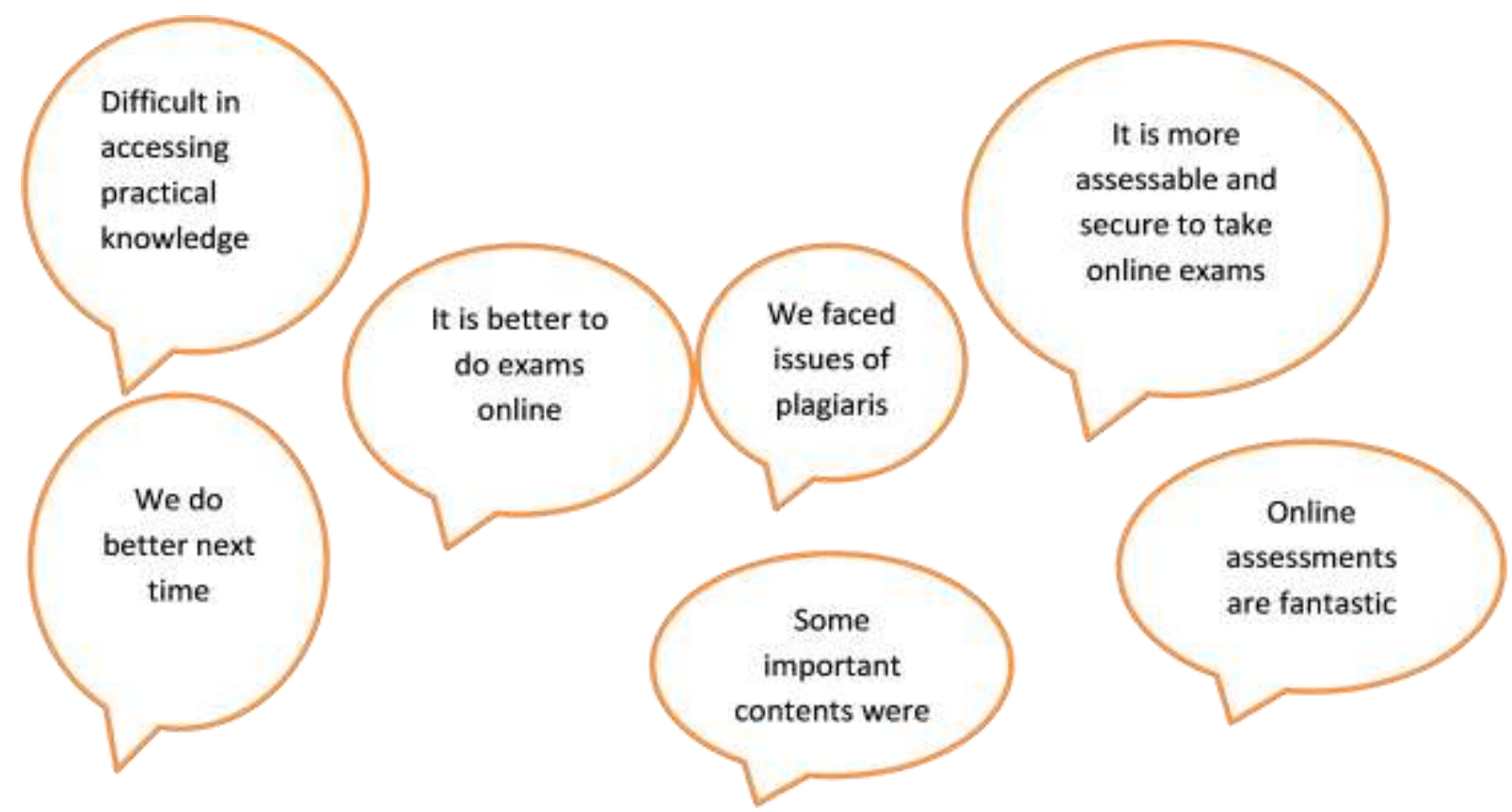

\section{Discussion}

Preliminary analysis from the data revealed six major themes from the recently conducted online assessments at STEP Institute of Art, Design \& Management for the various Art \& Design 
undergraduate qualifications. However, the abilities related to online assessment resulted from the themes still need to be further improved. While talking about difficulties in measuring students' capabilities through online assessments, one of the assessors commented:

"We had faced difficulties in assessing the practical knowledge of students during online assessments. There are possibilities that some students may design parts of their projects by copying from the internet."

A prominent finding is the issue of content coverage in online assessments. It is greatly felt that students' capabilities in Art \& Design subjects are difficult to completely judge through online assessments, resulting in non-coverage of $100 \%$ expected learning outcomes coverage in assessments. Considering the example of the unit "Digital fabric printing", the areas that seem problematic while covering as exam content include the display of products created through formative assessments, and execution of final product as a summative assessment, which included the model of final project, and printing of the project. Even though the initial stages of product development, i.e. surface designing, pattern designing, digital design making could be comparatively conveniently covered and assessed online, the need of assessing the final stages, nevertheless, remains there. The focus group discussion on this issue also revealed most teachers accept the problem of not covering the complete or desired contents through online assessment. Quoting one subject specialist and assessor;

"It was for the first time we were using technology for online assessments of such designoriented subjects. The situation suddenly arrived in the middle of the semester and we had less time to explore more options for online assessment. This resulted in non-coverage of some content that could not be ignored while mapping students' learning outcomes. I plan to re-assess the missing content in the follow-up unit next semester".

The program specialist and Quality Auditor also expressed her views. According to her, some of the missing content is important to cover to judge any student's theoretical and practical knowledge of the subject. On the other hand, she also thought other units are being assessed online, which were even more accurately evaluated through these computer-based assessments. Another assessor put this point succinctly as:

"In the context of my subject, I found online assessments better and effective, comparing to its paper-based counterpart. I also realize that generally, my students have shown a better sense of expression with meaningful annotation and effective writing skills, since students had to ensure they can explain in writing, the conceptual and logical flow of ideas and product development, which otherwise seems an easy task when they have to explain the same tasks during face to face assessments".

A lot of these findings from this discussion were not unexpected considering the assumption that students' subject-specific skills were assessed through online assessments for the first time. There seemed a consensus that knowledge-based outcomes are comparatively easier to assess online, comparing to skill-based learning outcomes. Additionally, the difference in students' attitudes showed no higher relationship with online assessments than the traditional regular assessment. Besides addressing the research questions, this study also helped in generalizing the under-researched area of conducting complex online assessments in the Art \& Design sector, which has not been executed previously and this calls for intensive standardization on conducting online assessments for in-service staff to cover all three learning domains; i.e. knowledge, skills, and attitude.

Other than the qualitative investigation, the quantitative analysis also identifies some key areas of research. Firstly, those students who were familiar with the IT techniques by studying it as a course in their previous degree were more comfortable in giving online exams. On the contrary, students who were using the technology for the first time prefer the traditional method of paper based assessments. Secondly, Art \& Design students found online assessments more accessible in giving their formative assessments and projects. This shows that distant learning programs related to art \& design courses would be beneficial for the learners. Thirdly, the quantitative analysis also highlights some important insights about the students with scholarships. Those students who are studying with scholarships consider online assessment as an important aspect of their education. Such students realized online assessment as a creative opportunity for showing their practical knowledge of the particular subject. Lastly, the majority of the students think that the content of their courses was covered as complete course content. This shows that in the context of art \& design subjects, online 
assessments help deliver the theoretical and practical knowledge of the subject (Netemeyer et al., 2003).

\section{Recommendations}

The data gained through quantitative research provides significant issues that could strongly build and complement the planning and implementation of online assessment strategies. Based on the findings from participants' responses, the following elements could be implied while designing the planning and implementation of online strategies for Art \& Design qualifications:

- $\quad$ Development of students' use and knowledge of IT

- $\quad$ Encouraging distant learning programs for art \& design subject

- Development of students' level of competence and seriousness towards education

- $\quad$ Development of Art \& Design Foundation for undergraduate students

\section{Conclusion}

The present study attempts to contribute and signify the under-researched areas while emphasizing the issue of the validity of online assessments with a prime focus on the role of computer-based assessment, specifically concerning the skill-oriented learning outcomes of different Art \& Design specialized courses. The paper attempts to relate the knowledge in existing literature by analyzing issues and aspects of online assessments. It reveals the comparatively untouched areas, including; a) using a complex form of online assessments that have been examined previously but not exclusively for the Art \& Design subjects, b) conducting the online assessments for Art \& Design learners to assess a complete set of learning outcomes that deal with all three learning domains, i.e. knowledge, skills, and attitude of learners towards the end of a course. Despite minimal variation, there is lesser evidence to suggest the point of view that online assessments dominantly deprive students who have lesser computer-related attitudes. On the contrary, it emphasizes a similar pattern of scoring among high and average performers. It highlights the comparatively more serious efforts of students who wish to retain their online assessment performance and consequently academic grades that sustain their academic scholarships. Furthermore, these findings encourage to explore further research areas, capacity building for assessors who are dealing mainly with practical and skill-based learning outcomes, and a further need of advocacy among students for their willingness and acceptance to perform better in their online assessments. The question of whether online assessments are valid and reliable is certainly not too easy to answer. Compliance for Art \& Design online assessments require not just familiarization but a competent understanding and rapid practices to be employed not considering it as the unwanted yet only option but as an alternative option for assessors as well as students. It is expected that these studies will develop a more rigorous, robust, and valid evidence for online assessment practices specifically in the Art \& Design sector. The study also helped in motivating assessors of the Institute of Art, Design \& Management to further exploring online forums, formats, methodologies, and means to conduct online assessments in the future.

The research study proposes recommendations to STEP Art \& Design faculty to consider issues that are highlighted by both quantitative and qualitative methods while planning and implementing appropriate strategies for a sustainable online education. These include: development of students' use and knowledge of IT, encouraging distant learning programs for art \& design subject, development of students' level of competence and seriousness towards education, and development of Art \& Design Foundation for undergraduate students suggested under the analysis of the quantitative method, whereas the qualitative research methodology suggest issues that need to be part of this strategy as: Enhancing students' capabilities, improvement in students' scores, focus on increasing assessment accuracy, ensure online assessments' Security and Accessibility, ensuring the completion of mandatory content coverage, and need of increased knowledge practices. The study recommends these elements if incorporated in the online teaching strategy of the faculty shall enable the construct validity of Art \& Design online education to successfully attain required students' learning outcomes.

\section{References}

Adelstein, D., \& Barbour, M. (2016). Building better courses: Examining the construct validity of the iNACOL national standards for quality online courses. Journal of Online Learning Research, 2(1), 41-73. 
Arias, J. J., Swinton, J., \& Anderson, K. (2018). Online vs. Face-to-Face: A Comparison of Student Outcomes with Random Assignment. e-Journal of Business Education and Scholarship of Teaching, 12(2), 1-23.

Allen, I. E., \& Seaman, J. (2014). Grade change: Tracking online education in the United States. Babson Survey Research Group.

Carmines, E. G., \& Zeller, R. A. (1979). Reliability and validity assessment (Vol. 17): Sage publications.

Chauhan, A. (2014). Massive open online courses (MOOCS): Emerging trends in assessment and accreditation. Digital Education Review(25), 7-17.

Ćukušić, M., Garača, Ž., \& Jadrić, M. (2014). Online self-assessment and students' success in higher education institutions. Computers \& Education, 72, 100-109.

Dumford, A. D., \& Miller, A. L. (2018). Online learning in higher education: exploring advantages and disadvantages for engagement. Journal of Computing in Higher Education, 30(3), $452-$ 465.

Guerrero-Roldán, A. E., \& Noguera, I. (2018). A model for aligning assessment with competencies and learning activities in online courses. The Internet and Higher Education, 38, 36-46.

Gikandi, J. W., Morrow, D., \& Davis, N. E. (2011). Online formative assessment in higher education: A review of the literature. Computers \& Education, 57(4), 2333-2351.

McCall, I. (2010). Online enhanced problem-based learning: assessing a blended learning framework. The Law Teacher, 44(1), 42-58.

McGrew, S., Breakstone, J., Ortega, T., Smith, M., \& Wineburg, S. (2018). Can students evaluate online sources? Learning from assessments of civic online reasoning. Theory \& Research in Social Education, 46(2), 165-193.

Netemeyer, R. G., Bearden, W. O., \& Sharma, S. (2003). Scaling procedures: Issues and applications: Sage Publications.

Nandini, V., \& Maheswari, P. U. (2020). Automatic assessment of descriptive answers in online examination system using semantic relational features. The Journal of Supercomputing, 76(6), 4430-4448.

Okada, A., Whitelock, D., Holmes, W., \& Edwards, C. (2019). e- Authentication for online assessment: A mixed- method study. British Journal of Educational Technology, 50(2), 861875.

Pedersen, E. R., Grow, J., Duncan, S., Neighbors, C., \& Larimer, M. E. (2012). Concurrent validity of an online version of the Timeline Followback assessment. Psychology of Addictive Behaviors, $26(3), 672$.

Poon, J. (2013). Blended learning: An institutional approach for enhancing students' learning experiences. Journal of online learning and teaching, 9(2), 271-288.

Tight, M. (2018). Tracking the scholarship of teaching and learning. Policy Reviews in Higher Education, 2(1), 61-78. 